Article

\title{
Porcine Alveolar Macrophages' Nitric Oxide Synthase-Mediated Generation of Nitric Oxide Exerts Important Defensive Effects against Glaesserella parasuis Infection
}

\author{
Qi Cao ${ }^{1,2,3,4}$, Huan Wang 1,2,3,4, Wenbin Wei 1,2,3,4, Yujin Lv ${ }^{1,2,3,5}$, Zhao Wen 1,2,3,4, \\ Xiaojuan $\mathrm{Xu}{ }^{1,2,3,4}$, Xuwang Cai ${ }^{1,2,3,4}$, Huanchun Chen ${ }^{1,2,3,4}$ and Xiangru Wang $1,2,3,4, *$ (D) \\ 1 State Key Laboratory of Agricultural Microbiology, College of Veterinary Medicine, Huazhong Agricultural \\ University, Wuhan 430070, Hubei, China; cq20100804@163.com (Q.C.); pinkapplewh@163.com (H.W.); \\ wenbWei@163.com (W.W.); 80775@hnuahe.edu.cn (Y.L.); witerswenzhao@163.com (Z.W.); \\ xuxiaojuan@mail.hzau.edu.cn (X.X.); caixuwang@mail.hzau.edu.cn (X.C.); chenhch@mail.hzau.edu.cn (H.C.) \\ 2 Key Laboratory of Preventive Veterinary Medicine in Hubei Province, The Cooperative Innovation Center \\ for Sustainable Pig Production, Wuhan 430070, Hubei, China \\ 3 Key Laboratory of Development of Veterinary Diagnostic Products, Ministry of Agriculture of the People's \\ Republic of China, Wuhan 430070, Hubei, China \\ 4 International Research Center for Animal Disease, Ministry of Science and Technology of the People's \\ Republic of China, Wuhan 430070, Hubei, China \\ 5 College of Veterinary Medicine, Henan University of Animal Husbandry and Economy, \\ Zhengzhou 471000, Henan, China \\ * Correspondence: wangxr228@mail.hzau.edu.cn
}

Received: 22 October 2019; Accepted: 11 November 2019; Published: 13 November 2019

\begin{abstract}
Glaesserella parasuis is a habitual bacterium of pigs' upper respiratory tracts. Its infection initiates with the invasion and colonization of the lower respiratory tracts of pigs, and develops as the bacteria survive host pulmonary defenses and clearance by alveolar macrophages. Alveolar macrophage-derived nitric oxide (NO) is recognized as an important mediator that exerts antimicrobial activity as well as immunomodulatory effects. In this study, we investigated the effects and the signaling pathway of $\mathrm{NO}$ generation in porcine alveolar macrophages 3D4/21 during G. parasuis infection. We demonstrated a time and dose-dependent generation of NO in 3D4/21 cells by G. parasuis, and showed that NO production required bacterial viability and nitric oxide synthase 2 upregulation, which was largely contributed by G. parasuis-induced nuclear factor- $\mathrm{kB}$ signaling's activation. Moreover, the porcine alveolar macrophage-derived NO exhibited prominent bacteriostatic effects against G. parasuis and positive host immunomodulation effects by inducing the production of cytokines and chemokines during infection. G. parasuis in turn, selectively upregulated several nitrate reductase genes to better survive this NO stress, revealing a battle of wits during the bacteria-host interactions. To our knowledge, this is the first direct demonstration of NO production and its anti-infection effects in alveolar macrophages with G. parasuis infection.
\end{abstract}

Keywords: Glaesserella parasuis; porcine alveolar macrophages; nitric oxide; NOS2; NF-кB signaling

\section{Introduction}

Glaesserella parasuis is the causative agent of porcine Glässer's disease, which is characterized by polyarthritis, fibrinous polyserositis and meningitis [1,2]. It is considered one of the most important opportunistic bacterial pathogens in nursery piglets, with the ability to cause high morbidity and mortality in China [3]. It is an early colonizer of the upper respiratory tract and part of the normal 
microbiata of healthy pigs [4]. Under certain circumstances, some highly virulent strains can invade the lungs and the circulatory system, and cause the subsequent multiple-systemic polyserositis [5].

Based on the infection dynamics, G. parasuis infections initiate from the invasion and colonization of the lower respiratory tract of pigs, and breakthrough host pulmonary defenses and clearance [6]. During these interaction processes, G. parasuis has to compete with lung-resident alveolar macrophages, which play essential roles in the first-line of host defense. This mainly involves the production and release of pro-inflammatory factors, such as interleukin- 8 and macrophage inflammatory protein- $1 \beta$; and antimicrobial bioactive molecules, such as reactive oxygen species or reactive nitrogen species (RNS) [7-9]. Usually, the innate immune system employs pathogen-associated molecular patterns (PAMPs), such as Toll-like receptors and nucleotide oligomerization domain-like receptors, to detect bacterial products and trigger innate immune responses [10,11].

Nitric oxide (NO) production is an important mechanism of the mammalian innate immune response [12]. Generally, mammalian cell NO is production from L-arginine catalyzed by three nitric oxide synthase (NOS) isoforms: neuronal NOS (NOS1), endothelial NOS (NOS3) and inducible NOS (NOS2) [13,14]. NOS1 and NOS3, mainly expressed in neurons and endothelial cells, respectively, catalyze the low generation of NO that is specifically involved in the regulation of neuronal cell differentiation or microvascular permeability $[15,16]$. In contrast, NOS2 is widely distributed in multiple cell types, and is significantly induced under certain infection or inflammatory stimulations via PAMPs $[17,18]$. For example, microbe-induced NOS2 production can be facilitated by myeloid differentiation factor 88 and the caspase adaptor recruitment domain family member-9-mediated nuclear factor (NF)- $\mathrm{kB}$ signaling pathway in a calcium-independent manner $[19,20]$.

The antimicrobial activity of NO and NOS2 has been reported within macrophages and other myeloid cells in many studies [21,22]. NO, catalyzed by NOS2, reacts with structural elements, components of replication machinery, nucleic acids, metabolic enzymes and virulence-associated molecules of infectious pathogens [21]. It inactivates the enzymatic activity of the $\mathrm{Fe}-\mathrm{S}$ metalloproteins, and mediates NO-dependent killing of Burkholderia mallei [23]. NO also interferes with the tricarboxylic acid cycle to inactivate the dihydrolipoyl dehydrogenase component of $\alpha$-ketoglutarate dehydrogenase in Salmonella enterica serovar Typhimurium [24]. Moreover, NO treatment combined with amoxicillin and clavulanic acid enhanced the ex vivo killing of Streptococcus pneumoniae in adenoid tissue [25]. However, elevated levels of NO from the persistent activation of NOS2 may lead to adverse effects on the host; for example, allograft rejection, septic shock and neurodegeneration [26-28]. Additionally, the NO produced by NOS2 catalyzation plays an important role in the development of osteoarthritis, in which NO overgeneration inhibits matrix synthesis and promotes cartilage breakdown and pain [29]. However, little is known about NO generation in alveolar macrophages in response to G. parasuis infection. The specific effects of NO involvement in antimicrobial activity and host innate immunity against $G$. parasuis have not been investigated.

Here, we report G. parasuis infection-induced NO generation in the porcine alveolar macrophage cell line 3D4/21. We investigated both the potential influence and signaling transduction pathway of NO generation in 3D4/21 cells in response to G. parasuis. We demonstrated positive host immunomodulation effects by releasing notable NO production in 3D4/21 cells after G. parasuis infection. NO showed both inhibitory effects on bacterial growth and immune activation effects on 3D4/21 cells, and G. parasuis in turn, selectively altered its gene expression to better survive these detrimental influences. The characterization of NO production and its potential effects in response to G. parasuis infection expanded our knowledge of G. parasuis pathogenesis from the perspective of pathogens and host interactions, which will better facilitate the prevention and control of this disease.

\section{Results}

\subsection{G. parasuis SH0165 Infection of 3D4/21 Cells Induces the Production of NO That Depends on Bacterial Viability}

The production of RNS by macrophages is recognized as an important part of the host immune defense against bacterial pathogens [30,31]. Here, the porcine alveolar macrophage cell line 3D4/21 was 
used to investigate possible NO production during its exposure to G. parasuis SH0165. NO production was measured and reflected by the accumulation of nitrite in the culture medium via the Griess reaction [32]. As shown in Figure 1a, there was no detectable NO production by 3D4/21 cells or bacteria alone during $12 \mathrm{~h}$ of observation. When challenged by the $\mathrm{SH} 0165$ strain, a significant induction of $\mathrm{NO}$ was observed over time. Interestingly, a faster generation of NO detected following a higher multiplicity of infection (MOI) applied.

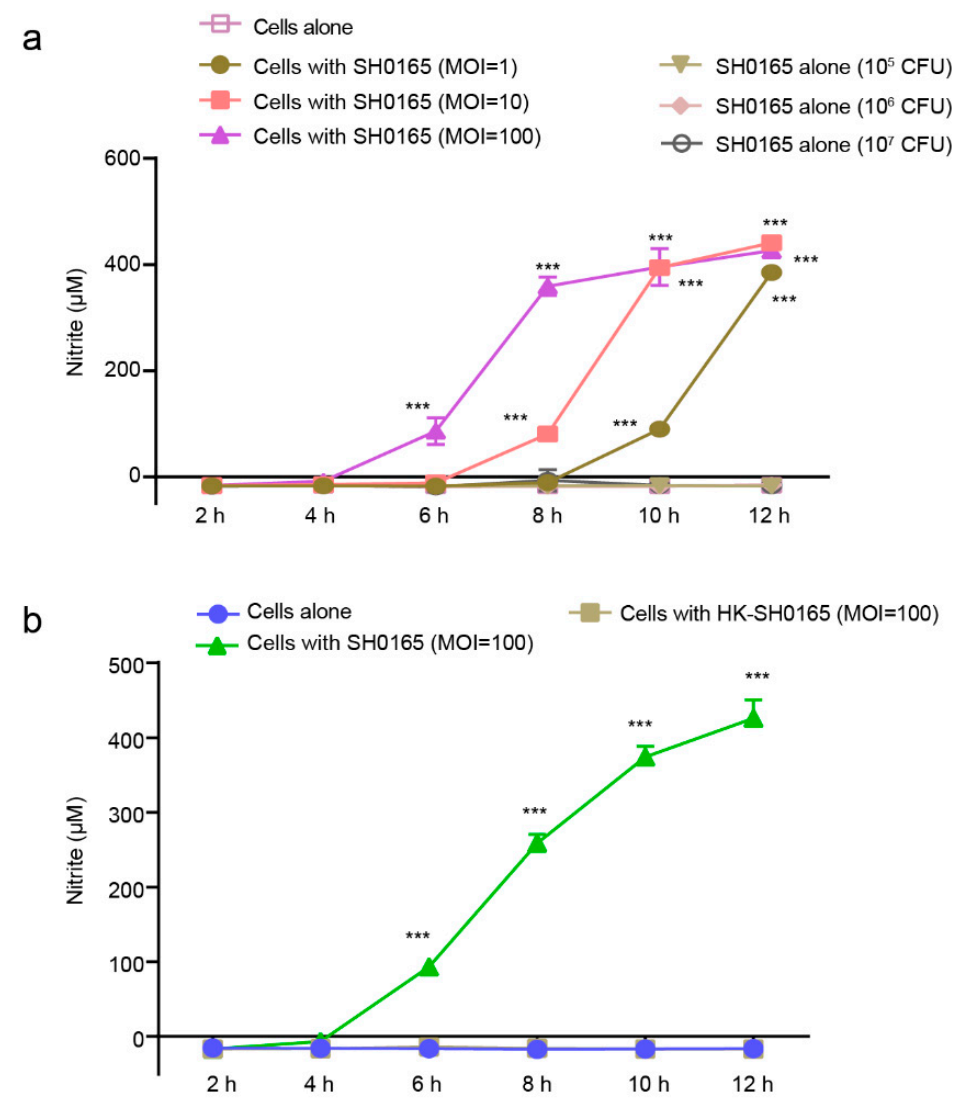

Figure 1. Glaesserella parasuis induced the time-dependent and multiplicity of infection (MOI)-dependent production of nitrite in 3D4/21 cells which required bacterial viability. (a) 3D4/21 cells were challenged with or without different doses (MOI of 1, 10 and 100) of SH0165 for $12 \mathrm{~h}$. (b) 3D4/21 cells were infected with SH0165 (MOI 100) or HK-SH0165 at the same MOIs for $12 \mathrm{~h}$. The supernatants were collected for nitrite measurement at $2 \mathrm{~h}$ intervals via the Griess reaction. Cells alone and bacteria alone at different colony forming units were used as controls. Data are shown as the means \pm SDs from three replicates. Statistical differences were analyzed using the Student's $t$-test $\left.{ }^{* * *}, p<0.001\right)$.

Because only a few prokaryotic organisms have mammalian NOS homologs, such as Staphylococcus aureus [33], Bacillus anthracis [34,35] and the plant pathogen Streptomyces turgidiscabies [36], and the fact that genome sequencing analysis revealed that G. parasuis SH0165 (accession number NC_011852.1) lacks bacterial NOS [37], we investigated NO production in culture medium next, by incubating 3D4/21 cells with either viable SH0165 or heat-killed SH0165 (HK-SH0165). We observed a significant and time-dependent induction of NO in 3D4/21 cells in response to viable SH0165 over $12 \mathrm{~h}$ of incubation, but found heat-inactivated bacteria were not able to stimulate NO generation (Figure 1b), suggesting its induction strictly depends on the viable SH0165 interaction with host cells. Together, these data suggest that SH0165 strains have the ability to induce the generation of NO in porcine alveolar macrophages, which largely requires bacterial viability. 
2.2. Cellular Inducible NOS2 and Cationic Amino Acid Transporter 2 (CAT2) are Responsible for NO Generation in 3D4/21 Cells Upon G. parasuis Infection

NO is normally generated via catalyzation of NOS, so we determined which NOS isoform is involved in G. parasuis-induced NO production. As shown in Figure 2a, we observed significantly increased expression of NOS2, but not NOS1 or NOS3, in response to $12 \mathrm{~h}$ of SH0165 infection. This induction was both time-dependent and bacterial MOI-dependent in 3D4/21 cells in response to SH0165 infection (Figure 2b). We also noticed that the NOS2 induction required bacterial viability because HK-SH0165 was not able to mediate NOS2 upregulation, while viable bacteria significantly induced NOS2 upregulation (Figure 2c).
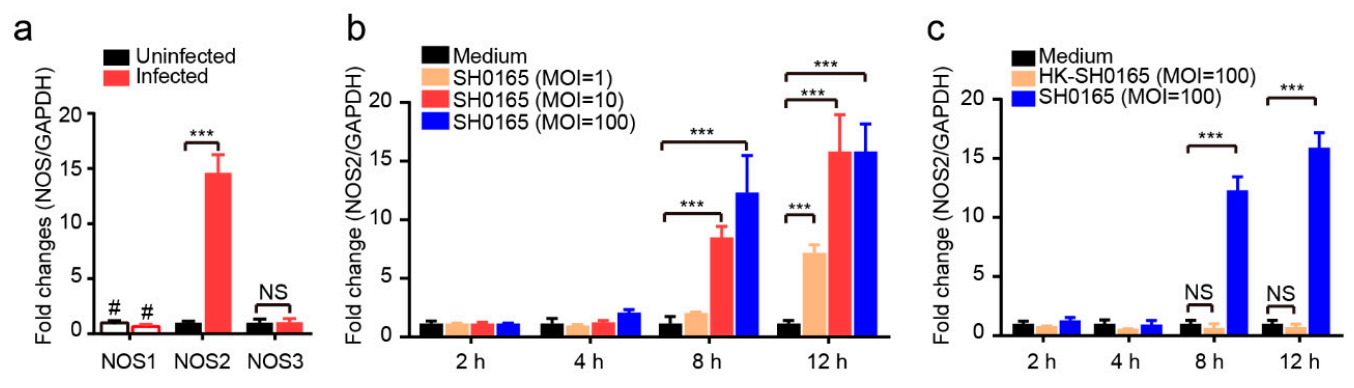

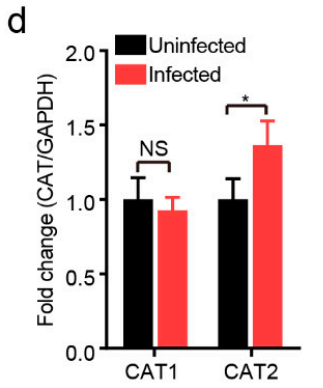

f

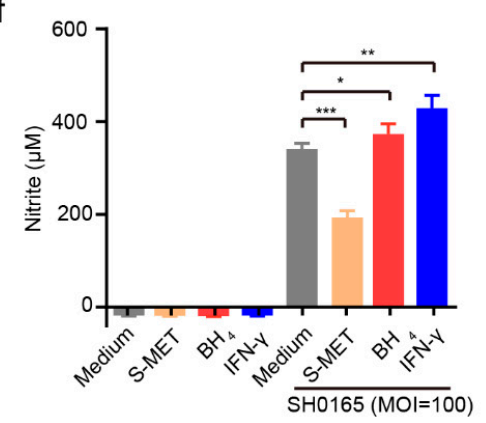

e

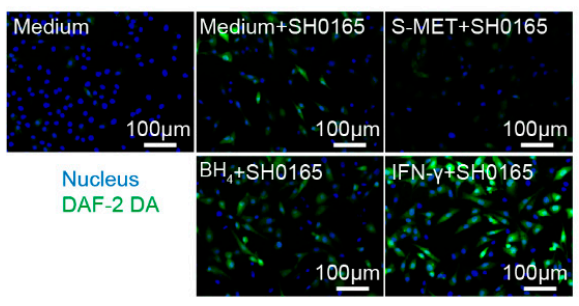

g

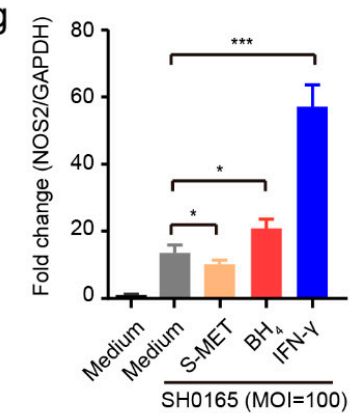

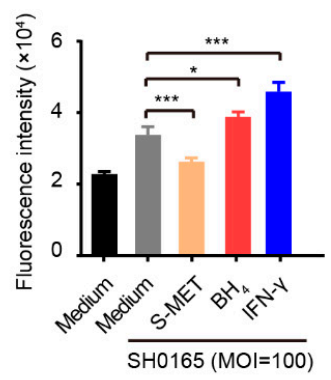

Figure 2. NOS2 and CAT2 facilitated G. parasuis-induced NO production. (a) Real-time PCR analyzing the expression levels of NOS isoforms in 3D4/21 cells in response to SH0165 infection for $12 \mathrm{~h}$. (b) Real-time PCR analysis of NOS2 expression in 3D4/21 cells in response to different infection doses of SH0165 at indicated time points. (c) NOS2 expression in 3D4/21 cells challenged with SH0165 or HK-SH0165 at indicated time points were analyzed by real-time PCR. (d) CAT expression levels in 3D4/21 cells infected with or without SH0165 for $12 \mathrm{~h}$. (e) Intracellular NO generation at $12 \mathrm{~h}$ of SH0165 infection at MOI of 100 was detected by the DAF-2 DA probe via fluorescence microscope capture and quantified with a fluorescence microplate reader. Scale bar, $100 \mu \mathrm{m}$. (f) Nitrite levels from culture supernatants of cells with or without SH0165 infection and other treatments at $12 \mathrm{~h}$ via the Griess reaction. (g) Real-time PCR analysis and comparison of NOS2 expression in SH0165-infected 3D4/21 cells receiving other treatments. All real-time PCR results were normalized to GAPDH and shown as means \pm SDs from three independent assays. Statistical differences were calculated using two-way ANOVA $\left({ }^{* * *}, p<0.001 ;{ }^{* *}, p<0.01 ;{ }^{*}, p<0.05\right.$; NS: not significant). \#, undetectable. 
Arginine can be transported into the cytoplasm to support NO generation, which requires cationic amino acid transporters CAT1 and CAT2 in macrophages [38,39]. We observed a significant increase in CAT2 in 3D4/21 cells $12 \mathrm{~h}$ post infection, while CAT1 was unaffected by the challenge, indicating that cellular CAT2 participates in NO synthesis in response to G. parasuis infection (Figure 2d).

To further validate the participation of NOS2 in G. parasuis-induced NO production, we applied the NOS2 inhibitor S-MET $(50 \mu \mathrm{M})$, the NOS2 enzymatic activity co-factor BH4 $(50 \mu \mathrm{M})$ and the positive stimulator IFN- $\gamma\left(50 \mathrm{ng} \cdot \mathrm{mL}^{-1}\right)$. The membrane-permeable NO probe DAF-2 DA [40] was used to indicate intracellular NO production in 3D4/21 cells upon challenge. As shown in Figure 2e, G. parasuis SH0165 infection of 3D4/21 cells significantly increased the generation of intracellular NO, which was prevented by S-MET pre-treatment. Moreover, BH4 significantly enhanced NO synthesis in SH0165-infected cells, while IFN- $\gamma$ significantly stimulated NO production upon SH0165 challenge. The nitrite concentration was discovered to be, in the culture medium, like that seen following intracellular NO generation (Figure 2f). The analysis of NOS2 transcriptional levels revealed a significant induction of transcription in response to SH0165, which was significantly decreased by S-MET treatment. As expected, both BH4 and IFN- $\gamma$ positively upregulated NOS2 transcription, which exhibited a similar pattern to that of intracellular NO generation and nitrite production (Figure $2 \mathrm{~g}$ ). Taken together, these findings suggest that G. parasuis infection of 3D4/21 cells significantly upregulates NOS2 as well as CAT2 for the induction of NO generation.

\subsection{NO Exerts an Inhibitory Effect on G. parasuis Growth and Proinflammatory Activation in 3D4/21 Cells}

Next, we investigated the potential effects of NO on bacteria and cells. Following addition of the exogenous NO donor SNP $\left(10 \mu \mathrm{g} \cdot \mathrm{mL}^{-1}\right.$ to $\left.200 \mu \mathrm{g} \cdot \mathrm{mL}^{-1}\right)$, the exogenous addition of NO significantly inhibited the growth of G. parasuis SH0165 in a dose-dependent manner compared with the SH0165 strain alone over a $24 \mathrm{~h}$ period (Figure 3a). Since NO showed an inhibitory effect on the viability of $G$. parasuis, we subsequently investigated the potential reactions of G. parasuis in response to the NO challenge. The possible metabolic or protein translation-associated genes, and the potential NO-responsive genes, such as the cytochrome biosynthesis and assembly genes, anaerobic metabolism genes, nitrate reductase genes, iron-sulfur cluster repair genes, NO detoxification genes and tricarboxylic acid cycle-involved genes [24,25,41], were tested by using real-time PCR on bacteria at the mid-logarithmic phase receiving $5 \mu \mathrm{g} \cdot \mathrm{mL}^{-1}$ of SNP for $2 \mathrm{~h}$. Our findings showed that SNP treatment significantly upregulated transcription of the anaerobic metabolism $n r d G$ gene, and the nitrate reductase nap $A$, napD, $n r f C$ and $n r f D$ genes (Figure $3 b$ ), revealing a protective feedback of gene regulation in G. parasuis when challenged by NO. These data together revealed that NO exhibits a strong bacteriostatic effect and induces a protective adaption of G. parasuis by feedback upregulating several NO-responsive genes.

As an important immune mediator, we examined the potential effects of $\mathrm{NO}$ on regulating inflammatory cytokines and chemokines in 3D4/21 cells. Cells were treated with or without $50 \mu \mathrm{g} \cdot \mathrm{mL}^{-1}$ SNP or challenged by SH0165 (MOI 100) with or without $100 \mu \mathrm{M}$ S-MET. The exogenous addition of NO induced significant upregulations of several proinflammatory factors, such as interleukin-6 (IL-6), granulocyte-macrophage colony-stimulating factor (GM-CSF) and chemokine (C-C motif) ligand 2 (CCL2) in 3D4/21 cells, suggesting an elevated inflammatory response mediated by NO. We also observed a significant induction of IL-6, GM-CSF and CCL2 by SH0165 infection in 3D4/21 cells, even higher than that induced by SNP treatment; however, this was largely inhibited by S-MET (Figure 3c), implying that NOS2-mediated NO production contributes to proinflammatory activation in alveolar macrophages during G. parasuis infection. 

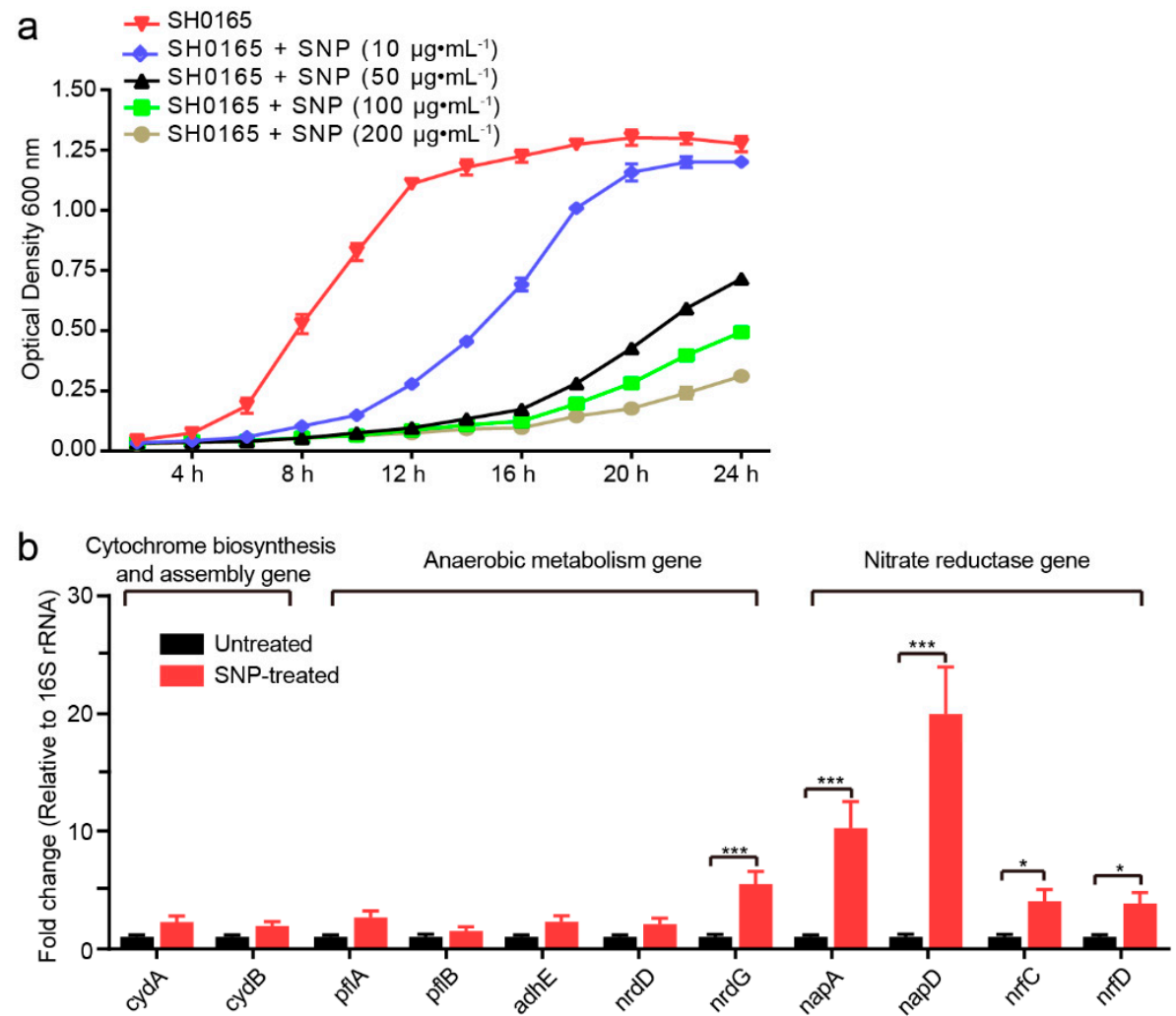

C

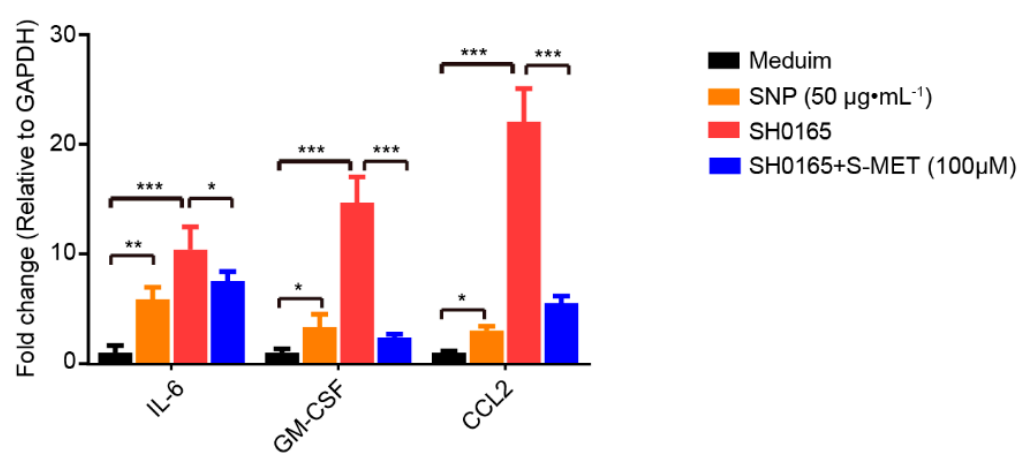

Figure 3. NO reduced the in vitro growth of G. parasuis and induced proinflammatory cytokine and chemokine expression in 3D4/21 cells. (a) The NO donor SNP exhibited a dose-dependent inhibition on the growth of G. parasuis SH0165. (b) Real-time PCR detection of multiple NO response-associated genes in G. parasuis SH0165, including cytochrome biosynthesis and assembly genes (cydAB), anaerobic metabolism genes ( $p f l A B, a d h E$ and $n r d D G$ ) and nitrate reductase genes (nap $A D$ and $n r f C D$ ). (c) Real-time PCR analysis of cytokine and chemokine expression in 3D4/21 cells receiving SNP $\left(50 \mu \mathrm{g} \cdot \mathrm{mL}^{-1}\right)$, SH0165 or SH0165 with pretreatment of S-MET $(100 \mu \mathrm{M})$ for $24 \mathrm{~h}$. Cells with medium alone were used as the control group. Results were generated from three duplicate assays and were normalized to bacterial $16 \mathrm{~S}$ rRNA or GAPDH of cells. Statistical differences were analyzed using two-way ANOVA $\left.{ }^{* * *}, p<0.0011^{* *}, p<0.011^{*}, p<0.05\right)$.

\subsection{G. parasuis' Activation of NF- $\kappa B$ Signaling Mediates NO Generation in $3 D 4 / 21$ Cells}

Previous studies have reported the activation of NF-кB signaling in PK-15 cells upon G. parasuis infection [42]. In 3D4/21 cells, we also observed the significant activation of NF- $\mathrm{B}$ signaling in response to G. parasuis, by the demonstration of time-dependent and MOI-dependent phosphorylation of the p65 subunit (Figure 4a). We found that activation of the p65 subunit required bacterial viability because p65 phosphorylation was significantly attenuated when cells were challenged by HK-SH0165 (Figure $4 b$ ). We also observed the significant and time-dependent degradation of IkB- $\alpha$ in 3D4/21 cells 
upon SH0165 infection (Figure 4c), further supporting the fact that G. parasuis infection of 3D4/21 cells induces the activation of NF- $\mathrm{KB}$ signaling. Two NF- $\mathrm{kB}$ signaling inhibitors, BAY11-7082 and CAY10657, significantly decreased SH0165-induced upregulation of NOS2 in a dose-dependent manner (Figure 4d), and significantly attenuated the SH0165-induced intracellular NO fluorescence intensity (Figure 4e).

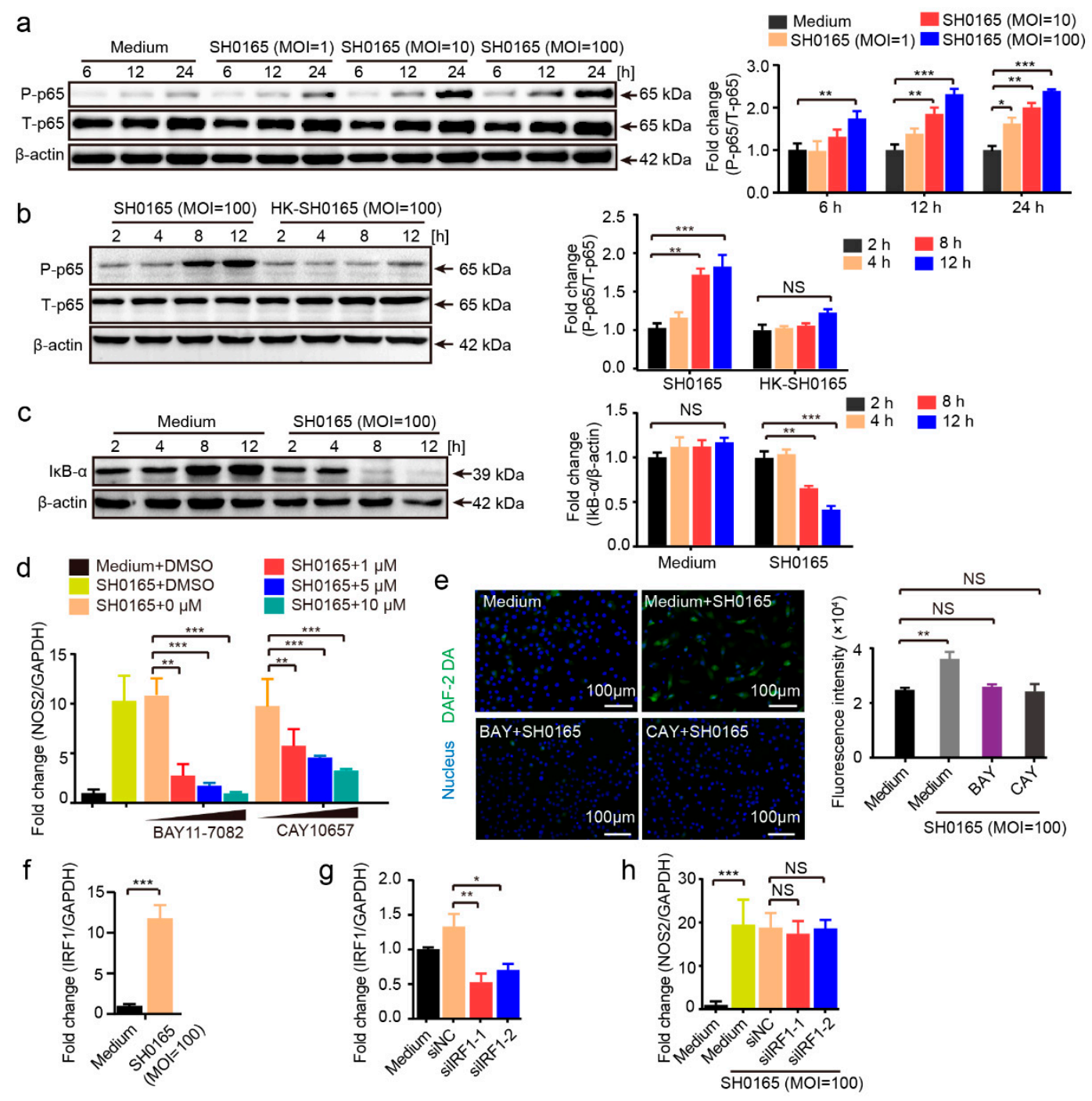

Figure 4. SH0165-induced activation of NF- $\mathrm{kB}$ signaling pathway-mediated NO generation in 3D4/21 cells. (a) Western blot showing time-dependent and bacterial MOI-dependent phosphorylation of the NF-kB p65 subunit in 3D4/21 cells in response to SH0165. (b) Western blot and comparison of p65 phosphorylation in response to SH0165 and HK-SH0165 (MOI 100) at the time points indicated. (c) Western blot analysis of IKB- $\alpha$ degradation in whole-cell lysates of 3D4/21 cells with or without SH0165 infection. (d) Real-time PCR analysis of NOS2 expression in 3D4/21 cells upon $12 \mathrm{~h}$ of SH0165 infection (MOI 100) with or without pretreatment of BAY11-7082 or CAY10657. (e) Intracellular NO generation at $12 \mathrm{~h}$ of infection at MOI of 100 was detected by the DAF-2 DA probe via fluorescence microscope and quantified with a fluorescence microplate reader. Scale bar, $100 \mu \mathrm{m}$. (f) Real-time PCR analysis of IRF1 expression in 3D4/21 cells upon SH0165 infection. (g) Cells were collected $24 \mathrm{~h}$ after siRNA transfection and real-time PCR analysis of IRF1 expression. NC, negative control. (h) IRF1 silencing by siRNA and was then infected with SH0165 or non-infected for $12 \mathrm{~h}$. Real-time PCR analysis of IRF1 expression in 3D4/21 cells. Band densitometry was normalized to T-p65 or $\beta$-actin and shown as mean \pm SD from three independent analyses. All real-time PCR data were normalized to GAPDH and shown as means \pm SDs from three independent assays. Statistical differences were analyzed using Student's $t$-tests ${ }^{* * *}, p<0.001 ;{ }^{* *}, p<0.01 ;{ }^{*}, p<0.05$; NS: not significant). 
Interferon regulatory factor 1 (IRF1) overexpression in HEK293T cells was previously shown to enhance the transcriptional activity of endogenous human NOS2 gene expression [43]. To determine whether IRF1 functions in response to G. parasuis infection, 3D4/21 cells were incubated with SH0165 (MOI 100) for $12 \mathrm{~h}$, and the expression of IRF1 was evaluated by real-time PCR. As shown, SH0165 infection of 3D4/21 cells significantly upregulated IRF1 (Figure 4f). However, silencing IRF1 expression by siRNA (Figure 4g) revealed that IRF1 knock-down did not significantly decrease NOS2 expression compared with the significant induction by SH0165 infection (Figure 4h). These data, therefore, suggest that the G. parasuis-induced increase of NOS2 transcription in 3D4/21 cells largely depends on the activation of NF-KB signaling, and does not occur via IRF1-mediated signaling.

To further support the role of NF- $\mathrm{KB}$ signaling in mediating NO production, the dual luciferase reporter assay was used to demonstrate the direct regulation of NF- $\mathrm{kB}$ signaling in NOS2 expression. As shown in Figure 5a, four potential NF- $\mathrm{kB}$ p65 binding sites (red triangles) and two potential IRF1 binding sites (blue triangles) on the promoter region of NOS2 were bioinformatically predicted (Figure 5a). Of these, NF- $\mathrm{kB}$ p65 Binding Site 3 appeared twice, at +55 to +65 and -1358 to -1348 (Figure $5 \mathrm{a}$ ). Based on the location of these binding sites, we constructed a luciferase reporter plasmid containing the full-length NOS2 promoter region $(\sim 1.9 \mathrm{~kb})$ and three different mutations. Deletion 1 ranged from -962 to +69 and contained three potential NF- $\mathrm{KB}$ p65 binding sites (sites 1, 2 and 3); deletion 2 ranged from -1901 to -961 and contained two potential IRF1 binding sites and one potential NF-KB p65 binding site (Site 3); and deletion 3 ranged from +76 to +106 and contained no NF-KB p65 or IRF1 binding sites (Figure 5b). p65 co-transfection with the full-length NOS2 promoter and deletion 1 induced similar and significantly higher luciferase activities compared with controls. p65 co-transfection with deletion 2 also significantly increased the luciferase activity compared with controls, which may be attributable to the p65 binding site 3 , but this activity was much lower than that of the full-length and deletion 1 constructs. This suggests that the deletion 1 region of -962 to +69 is essential for transcriptional activity of NOS2 mRNA (Figure 5b). p65 co-transfection with deletion 3 induced no luciferase activity, further supporting our bioinformatical prediction (Figure 5a,b). In contrast, IRF1 co-transfection with the different NOS2 promoter constructs did not increase luciferase activity (Figure 5b), confirming our observation that IRF1 does not participate in G. parasuis induction of NOS2 in 3D4/21 cells (Figure 4g). Subsequently, a set of mutations was introduced into the NOS2 promoter region containing the three $\mathrm{p} 65$ binding sites (binding site mutations 1, 2 and 3; Figure 5a) and their luciferase activities were compared with that of p65 co-transfection. Figure $5 c$ shows that the NOS2 promoter with the wild-type p65 binding site (red triangle) exhibited significantly higher luciferase activity compared with the vector control. When these $\mathrm{p} 65$ binding sites were mutated separately (grey triangle), an extremely significant decrease of NOS2 promoter activity was observed (Figure 5c). An even lower level of NOS2 luciferase activity was detected when all three p65 binding sites were mutated concurrently (Figure 5c), suggesting that they function together to facilitate NOS2 transcription. 
a

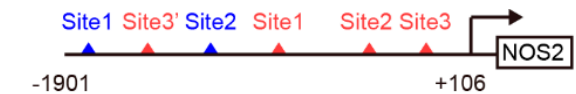

\begin{tabular}{|c|c|c|c|}
\hline NF-KB p65 Binding Site 1 & $5 ' \cdots$ G AGT GGG GGT TCC CTG GA $\cdots 3$ ' & -568 & $\rightarrow-558$ \\
\hline NF-KB p65 Binding Site 2 & $5 ' \cdots$ A TAT GGA GGT TCC CAG GC $\cdots 33^{\prime}$ & -149 & $\rightarrow-139$ \\
\hline NF-KB p65 Binding Site 3 & $5 ' \cdots$ T GAC GGG AAC TCC GCT GT $\cdots 3$ ' & +55 & $\rightarrow+65$ \\
\hline NF-KB p65 Binding Site 3' & $5 ' \cdots A$ GAC GGG AAC TCC GGAAA $\cdots 3$ ' & -1358 & $\rightarrow-1348$ \\
\hline IRF1 Binding Site 1 & $5 ' \cdots$ T ATT TTT CCC TTA AAT C $\cdots 3^{\prime}$ & -1793 & $\rightarrow-1784$ \\
\hline IRF1 Binding Site 2 & $5 ' \cdots$ C ATT TTT CCT TAG GGA T $\cdots 3^{\prime}$ & -1084 & $\rightarrow-1075$ \\
\hline binding site mutation 1 & $5^{\prime} \cdots$ G AGT AAA AAC CTT TTG GA $\cdots 3^{\prime}$ & & \\
\hline binding site mutation 2 & $5 ' \cdots$ A TAT AAG AAC CTT TAG GC $\cdots 3^{\prime}$ & & \\
\hline binding site mutation 3 & 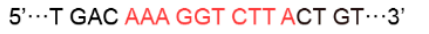 & & \\
\hline
\end{tabular}

b

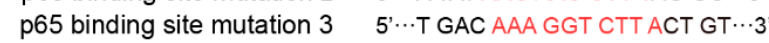

NOS2 promoter deletion 3 pcDNA3.1(+) - Vector
pcDNA3.1(+) - IRF1 pcDNA3.1(+) - p65

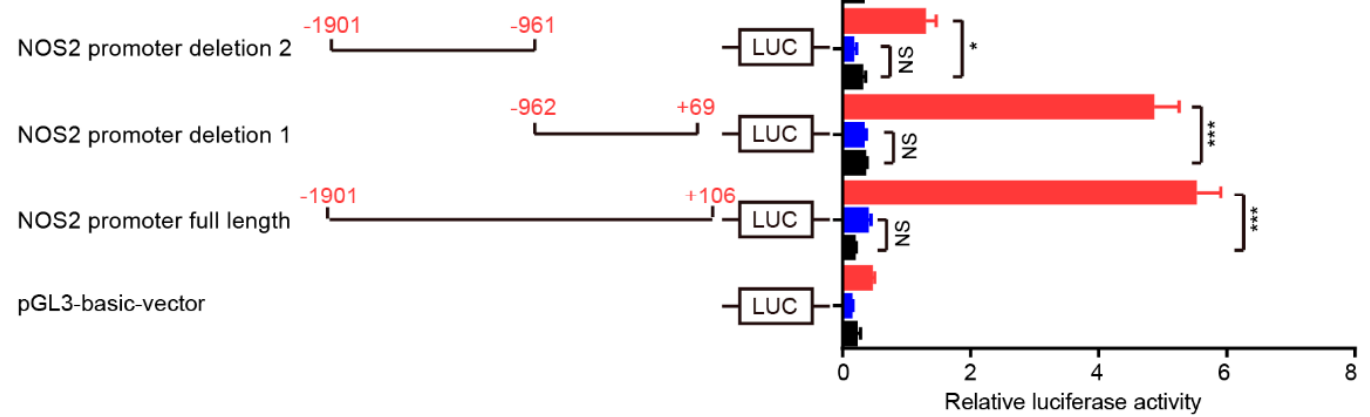

C

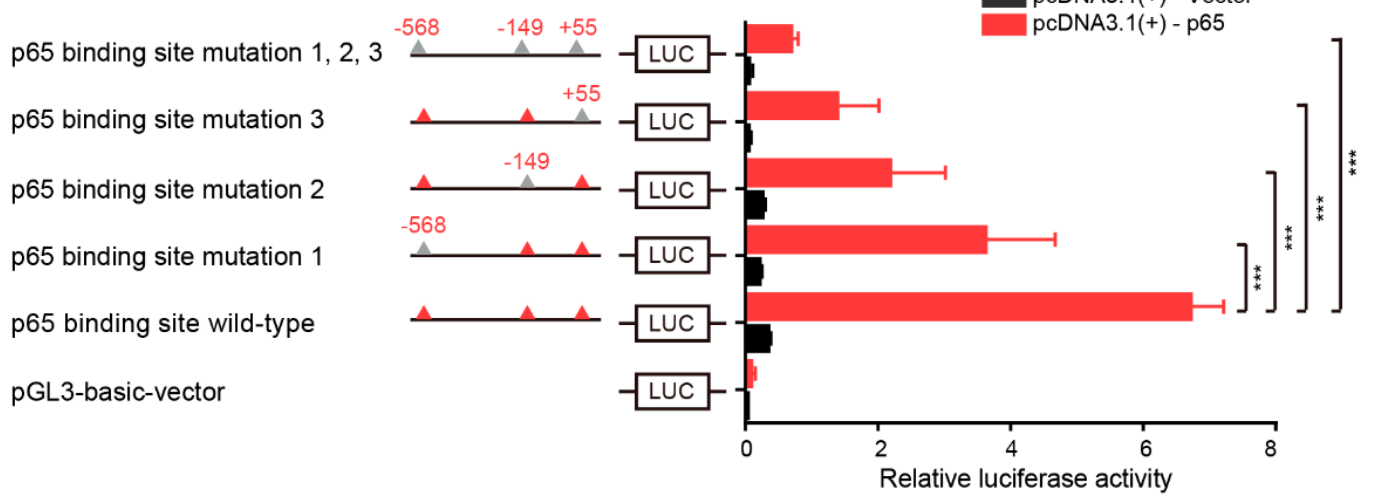

Figure 5. The effects of NF- $\mathrm{kB}$ p65 binding sites on the transcriptional activity of the NOS2 promoter via luciferase reporter assays. (a) The potential p65 binding sites (red triangles) and IRF1 binding sites (blue triangles) in the NOS2 promoter region. (b) The NOS2 full-length promoter region and different truncations were co-transfected with p65 or IRF1 to analyze and compare luciferase activities. (c) A set of p65 binding site mutations was introduced into the NOS2 promoter region and transcriptional activities were analyzed by luciferase reporter assays with p 65 co-transfection. Firefly luciferase activity was measured and normalized to Renilla luciferase activity. Results are expressed as means \pm SDs from six well duplicates. The statistical differences were calculated using two-way ANOVA ${ }^{* * *}, p<0.001$; $*, p<0.05$; NS: not significant).

\section{Discussion}

NO is an important endogenous bioactive mediator of macrophages that mediates multiple effects during microbial infections [44]. Several pieces of evidence have shown that the production of NO in macrophages is stimulated by pathogens such as S. aureus, Mycobacterium tuberculosis, Actinobacillus pleuropneumoniae and Blastomyces dermatitidis [7,45-47]. Mammalian NO is derived from the catalyzation of L-arginine by NOS under complex oxidoreductase reactions [17]. A previous study indicated that NOS2 is transcribed at low abundance in porcine immune cells [48], but we demonstrated a high level of NO production in porcine alveolar macrophages in response to G. parasuis infection. 
G. parasuis-induced NOS2 expression mediates the generation of NO in porcine alveolar macrophages, which largely requires bacterial viability. We observed time-dependent and bacterial MOI-dependent NO production and NOS2 expression in 3D4/21 cells, which was dependent on bacterial viability.

NOS2 activity can be regulated by cytokines or bacteria and affects GTP cyclohydrolase I, the key enzyme for BH4 synthesis, while BH4 is an essential component for NOS catalysis [12]. Similarly, IFN- $\gamma$ is a positive stimulator for the generation of $\mathrm{NO}$ [49], and an IFN- $\gamma$-activated site was previously detected in the NOS2 promoter region in mouse macrophages [50]. In the present study, treatment with $\mathrm{BH} 4$ or IFN- $\gamma$ during G. parasuis challenge greatly increased NOS2 transcription and significantly enhanced NO production. Noticeably, in the absence of G. parasuis challenge, these treatments had no effect on NO generation.

Our results provide solid evidence that G. parasuis activation of NF- $\kappa B$ signaling facilitates NOS2-mediated NO generation in 3D4/21 cells. Previous studies showed that IRF1 regulates the expression of murine NOS2 [51]. Here, we found that IRF1 was significantly upregulated in 3D4/21 cells upon G. parasuis infection. However, siRNA and dual-luciferase assays detected no regulatory effect of IRF1 on NOS2 expression; the luciferase assays also suggested that NOS2 transcriptional activity was independent of IRF1. Bioinformatics analysis identified four potential p65 binding sites in the promoter of NOS2, which is consistent with previous findings that NF- $\mathrm{KB}$ binds the human NOS2 promoter [52]. We also demonstrated the significant and time-dependent activation of NF- $\mathrm{kB}$ signaling in 3D4/21 cells in response to G. parasuis infection. Our pharmacological inhibitor assay subsequently revealed that NOS2 expression was largely increased by the activation of NF- $\mathrm{KB}$ signaling, and the luciferase assay showed that the $\mathrm{p} 65$ binding sites were all functionally involved in the transcriptional activity of the NOS2 promoter. These findings suggest the p65-triggered NF-KB signaling, but not IRF1-associated pathways, determines the NOS2-mediated generation of NO in porcine alveolar macrophages following G. parasuis challenge.

NOS2-mediated NO production contributes to proinflammatory activation in alveolar macrophages during G. parasuis infection. Importantly, NOS2-catalyzed reactive nitrogen intermediates have been reported to play important roles in mediating bactericidal activity, inhibiting bacterial infections and regulating inflammatory processes [53,54]. For example, uropathogenic Escherichia coli toxins induced the apoptosis of renal tubular epithelial cells via NOS, while the NO donor, SNP-mediated upregulation of heme oxygenase-1 prevented E. coli-induced apoptosis [39]. In enterohemorrhagic E. coli (EHEC), exogenously added or cellularly-derived NO inhibited spontaneous or mitomycin C-induced shiga-toxin (stx) mRNA transcription and Stx synthesis [55]. Additionally, the exogenous addition of NO restricted the intracellular growth of pathogenic Rhodococcus equi through depleting iron [32]. Moreover, studies have shown that NO inhibits EHEC adhesion of human intestinal epithelial cells [56], and suppresses Staphylococcal virulence by targeting the Agr quorum sensing system [57]. Here, we provide direct evidence that NO significantly inhibits the growth of G. parasuis, which could be recognized as an important protective strategy of macrophages. Meanwhile, NO exhibited potential pro-inflammatory activation effects by inducing the expression of multiple cytokines and chemokines in alveolar macrophages during G. parasuis infection. These findings, together, imply that alveolar macrophage-derived NO demonstrates important defensive effects against invading G. parasuis.

Bacterial pathogens have evolved a diverse range of strategies to overcome nitrative stresses and subvert host defenses. When exposed to a NO environment, Histoplasma capsulatum upregulates the expression of NO reductase to maintain or promote the secretion of virulence factors [58], while $S$. enterica Typhimurium induces a nitrative stress-resistance regulon that includes flavohemoglobin, a NO detoxifying enzyme required for bacterial virulence [59]. Although S. aureus lacks the NO-sensing transcriptional regulator NsrR, the bacterium uses its two-component system SrrAB to sense and respond to external nitrative stresses [41]. Using the iTRAQ approach, 13 proteins of $S$. pneumoniae were shown to be differentially expressed following low-concentration NO treatment, with $85 \%$ participating in metabolism or gene transcription [25]. We also investigated corresponding gene expression alterations in G. parasuis following low-concentration NO stimulation, and found that nitrate reductase 
genes (including nap $A, n a p D, n r f C$ and $n r f D$ ) were significantly upregulated. In contrast, cytochrome biosynthesis and assembly genes $(c y d A$ and $c y d B)$ were unaffected, and anaerobic metabolism genes, such as $p f l A, p f l B, a d h E$ and $n r d D$ (excluding $n r d G$ ), were also unchanged in response to the NO challenge. These findings suggest that the nitrate reductase genes are probably utilized by G. parasuis to survive NO-mediated bacteriostatic effects. This may be an environmental stress adaptive response mechanism evolved by G. parasuis during its interaction with its host.

In summary, we herein demonstrated the significant induction of $\mathrm{NO}$ generation in porcine alveolar macrophages by G. parasuis infection. The bacterial activation of NF-kB signaling mediated NOS2 upregulation and largely contributed to NO production, which plays an important role in magnifying the inflammatory responses. While $\mathrm{NO}$ (or nitrite) exhibits detrimental effects on the growth of G. parasuis, the bacterium, correspondingly, selectively upregulates multiple nitrate reductase genes to overcome the environmental stress. Overall, our current work provides novel insights regarding alveolar macrophage-derived NO into the pathogenesis of G. parasuis and the stress-responsive strategy of the bacterium (Figure 6). These findings increase our understanding of G. parasuis pathogenesis from the perspective of interactions between pathogens and hosts, which will contribute to better prevention and control of this disease.

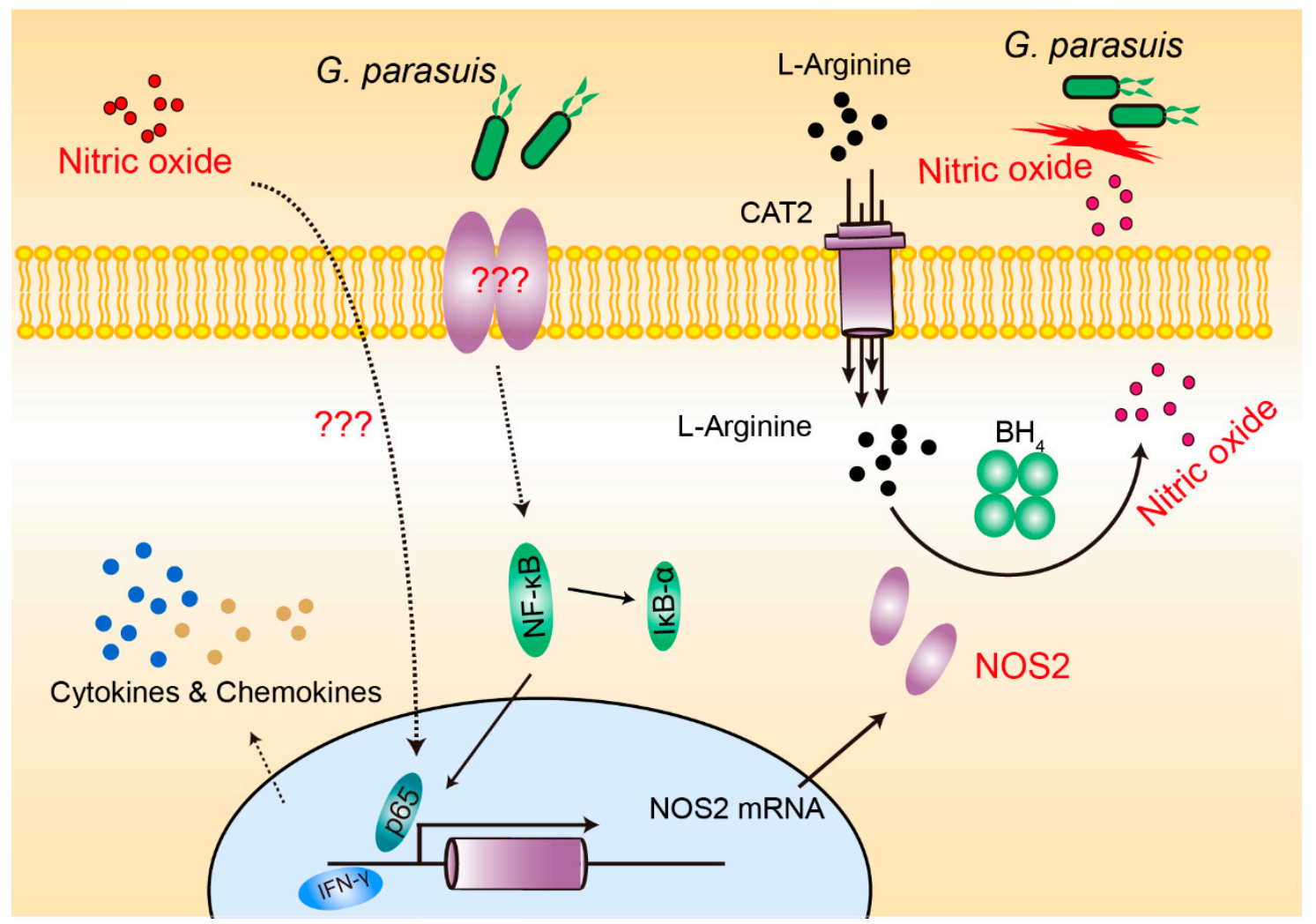

Figure 6. Schematic diagram of the pathways and molecules involved in this NO process in response to G. parasuis infection.

\section{Materials and Methods}

\subsection{Bacterial Strains and Cell Culture}

G. parasuis SH0165, whose whole genome we sequenced in a prior study [37], is a highly virulent serovar 5 strain clinically isolated from the lung of a diseased piglet in North China. Bacteria were cultured in tryptic soy broth (TSB) (Difco Laboratories, Detroit, MI, USA) or on tryptic soy agar (TSA) (Difco Laboratories) supplemented with $10 \mu \mathrm{g} / \mathrm{mL}$ nicotinamide adenine dinucleotide and 5\% $(\mathrm{v} / \mathrm{v})$ inactivated newborn bovine serum (TSA/V/S or TSB/V/S, respectively) at $37^{\circ} \mathrm{C}$ with $5 \% \mathrm{CO}_{2}$. 
Cultured bacteria were washed and resuspended in RPMI 1640 medium (Life technologies, Grand Island, NY, USA) before experimental use. To prepare HK-SH0165, cultured bacteria were incubated at $70{ }^{\circ} \mathrm{C}$ for $20 \mathrm{~min}$ then washed and resuspended in RPMI 1640 medium. Complete killing of the bacteria was confirmed by plating on TSA/V/S plates.

The porcine alveolar macrophage cell line 3D4/21 was obtained from American Type Culture Collection (ATCC, Manassas, USA) (no. CRL-2843). Cells were cultured and maintained in RPMI 1640 medium supplemented with $2 \mathrm{mM}$ L-glutamine, $1.5 \mathrm{~g} / \mathrm{L}$ sodium bicarbonate, $4.5 \mathrm{~g} / \mathrm{L}$ glucose, $10 \mathrm{mM}$ HEPES, $1.0 \mathrm{mM}$ sodium pyruvate, $0.1 \mathrm{mM}$ nonessential amino acids and $10 \%$ fetal bovine serum (FBS) at $37{ }^{\circ} \mathrm{C}$ with $5 \% \mathrm{CO}_{2}$. HEK293T cells (ATCC, no. CRL-11268) cell were cultured and maintained in Dulbecco's modification of Eagle's medium (DMEM) (Life technologies, Grand Island, NY, USA) supplemented with $10 \%$ FBS.

\subsection{Porcine Alveolar Macrophage Infection}

$3 \mathrm{D} 4 / 21$ cells were seeded in 24-well plates at $2 \times 10^{5}$ cells/well or in $60 \mathrm{~mm}$ dishes at $2 \times 10^{6}$ cells/dish, measured by using red blood cell counting plate. Confluent cells were treated with or without the NOS2 specific inhibitor S-Methylisothiourea hemisulfate salt (S-MET, Sigma-Aldrich, St Louis, MO, USA), the NF-kB inhibitor BAY11-7082 (Sigma-Aldrich), the inhibitor of NF-kB kinase (IKK) $\beta$ inhibitor CAY10657 (Cayman Chemical, Ann Arbor, MI, USA), IFN- $\gamma$ (Kingfisher Biotech, St Paul, MN, USA) or tetrahydrobiopterin (BH4, Sigma-Aldrich) prior to the SH0165 challenge at a MOI of 100, 10 and 1, or for the HK-SH0165 challenge at a MOI of 100.

\subsection{Growth Analysis of G. parasuis in Response to NO}

An overnight culture of G. parasuis SH0165 was diluted to an optical density at $600 \mathrm{~nm}\left(\mathrm{OD}_{600}\right)$ of 1.0, as previously described [60]. The diluted bacterial suspension was inoculated 1:100 into fresh TSB/V/S medium with or without the NO donor sodium nitroprusside (SNP, Sigma-Aldrich) and incubated at $37^{\circ} \mathrm{C}$ with circular agitation at $170 \mathrm{rpm} / \mathrm{min}$ for $24 \mathrm{~h}$. The $\mathrm{OD}_{600}$ of the cultures was measured by using an Eppendorf Biospectrometer (Eppendorf, Hamburg, Germany) at $2 \mathrm{~h}$ intervals. The assay was performed independently in triplicate.

\subsection{Nitrite Measurement and NO Detection}

3D4/21 cells were infected with SH0165 or HK-SH0165; then, culture supernatants were collected to measure the nitrite content using Griess reagent according to the manufacturer's instructions (Beyotime, Shanghai, China). Briefly, $50 \mu \mathrm{L}$ of both Griess reagent I and reagent II were added to $50 \mu \mathrm{L}$ of culture supernatants in 96 well-plates and incubated for $5 \mathrm{~min}$ at room temperature. The $\mathrm{A}_{540}$ was then measured with a microplate reader (Eppendorf, Hamburg, Germany). The nitrite content in each sample was calculated and normalized based on the standard curve of sodium nitrite with known concentrations.

Cellular NO production was detected using a cell-permeable fluorescent probe, (6'-Acetyloxy-5, 6-diamino-3-oxospiro [2-benzofuran-1, 9-xanthene]-3'-yl) acetate (DAF-2 DA, Abcam, Cambridge, MA, USA), as previously described [32]. In some assays, S-MET (50 $\mu \mathrm{M})$, IFN- $\gamma(50 \mathrm{ng} / \mathrm{mL})$ or BH4 $(20 \mu \mathrm{M})$ was maintained during the experiment. Cells were stained with $5 \mu \mathrm{M}$ of DAF-2 DA for $30 \mathrm{~min}$ and washed with phosphate-buffered saline (PBS) to remove extracellular DAF-2 DA. Subsequently, cells were fixed with $4 \%$ paraformaldehyde for $30 \mathrm{~min}$, washed three times with PBS and then stained with 4',6-diamidino-2-phenylindole-dihychloride for $4 \mathrm{~min}$. Cells in each well were finally washed with PBS, and then subjected to fluorescence intensity determination with a fluorescence microplate reader and image captured using a fluorescence microscope (EVOS FL Auto, Life Technologies corporation, Gaithersburg, MD, USA). 
4.5. Plasmid Construction, Cell Transfection, Small Interfering RNA Transfection and the Dual Luciferase Reporter Assay

The coding sequence (CDS) of p65 (Gene ID: 100135665) and the interferon regulatory factor 1 gene (IRF1, Gene ID: 396611) were amplified from cDNAs of 3D4/21 macrophages using Prime STAR Max DNA polymerase (Takara Bio Inc., Shiga, Japan), and then cloned into the pcDNA3.1(+) vector (Invitrogen, Carlsbad, CA, USA), using KpnI/EcoRI and XbaI restriction sites. The promoter region of NOS2 (Gene ID: 396859) was amplified and cloned into the pGL3-luciferase plasmid (Promega, Madison, WI, USA), using NheI and HindIII restriction sites. Plasmid cloning with p65 or IRF1 CDS and plasmids with the NOS2 promoter region were co-transfected into HEK293T cells using the jetPRIME transfection regent (Polyplus transfection, Illkirch, France) for subsequent dual luciferase reporter analysis. Briefly, cells were seeded in 24 -well plates at $1 \times 10^{5}$ cells/well and incubated for $24 \mathrm{~h}$. A total of $50 \mu \mathrm{L}$ of jetPRIME buffer; $200 \mathrm{ng}$ of plasmid DNA (pGL3-NOS2, pcDNA3.1(+)-p65, or pcDNA3.1(+)-IRF1); and 20 ng of control plasmid DNA pRL-TK, were mixed; then, $2 \mu L$ of jetPRIME reagent was added into the mixture and incubated at room temperature for 10 min prior to adding into 24 well-plates. Cells were cultured for $24 \mathrm{~h}$ and luciferase activity was measured using the dual-luciferase reporter assay system (Promega, Madison, WI, USA) according to the manufacturer's recommendations. Relative luciferase activity was calculated by the ratio of reporter and control activity (Firefly fluorescence) to that of control activity (Renilla fluorescence).

In the IRF1 small interfering (si) RNA knockdown assay, 40 pmol of IRF1 siRNA oligonucleotide (GenePharma, Suzhou, China) was transfected into 3D4/21 cells using jetPRIME regents. IRF1 and negative control siRNA sequences are shown in Table 1.

Table 1. Primers used in this study.

\begin{tabular}{|c|c|}
\hline Primer Name & Primer Sequence $\left(5^{\prime} \text { to } 3^{\prime}\right)^{1}$ \\
\hline NOS2-Promoter-F (NheI) & CATGCTAGCCAAGCATGCGTGCATATCTCC \\
\hline NOS2-Promoter-R (HindIII) & CCCAAGCTTGAGGTGACCTGACTCACGGA \\
\hline Promoter-Deletion 1-F (NheI) & CATGCTAGCAAAGAAATGGGTTGTGGGTG \\
\hline Promoter-Deletion 2-F (NheI) & CATGCTAGCCACCCTGTCTTGGTCCTTTG \\
\hline Promoter-Deletion 3-R (HindIII) & CCCAAGCTTAAGGGACAGAGGAGAGCATCTC \\
\hline Promoter-Mutation 1-F & AAAAACCTTTTGGATCCGGAGAGATATGG \\
\hline Promoter-Mutation 1-R & AAAGGTTTTTACTCTCGTCCAGGAATCTCCA \\
\hline Promoter-Mutation 2-F & AAGAACCTTTAGGCTAGGGGTTGAATCGG \\
\hline Promoter-Mutation 2-R & AAAGGTTCTTATATGCCACGGGAGCGGC \\
\hline Promoter-Mutation 3-F & AAAGGTCTTACTGTGAAGTTTTTATCCATGGGT \\
\hline Promoter-Mutation 3-R & TAAGACCTTTGTCATGGCGCAGTGGTTAAC \\
\hline p65-F $(K p n I)$ & GGGGTACCATGGACGACCTCTTCCСССT \\
\hline p65-R (XbaI) & GCTCTAGATTAGGAGCTGATCTGACTCA \\
\hline IRF1-F (EcoRI) & CCGGAATTCATGCCCATCACTCGGATG \\
\hline IRF1-R (XbaI) & GCTCTAGACTACGGTGCACAAGGAATG \\
\hline qIRF1-F & ACCGTGTGCCATCAGTAGTA \\
\hline qIRF1-R & CCTCCTCGTCCTCATCTGTT \\
\hline qGAPDH-F & CACAGTCAAGGCGGAGAAC \\
\hline qGAPDH-R & CGTAGCACCAGCATCACC \\
\hline qNOS1-F & GTCCAGACCTCAGAGACAACT \\
\hline qNOS1-R & CCACGCAGAACACATCACA \\
\hline qNOS2-F & AGCCTCTGGACCTCAACAA \\
\hline qNOS2-R & GCTGGATTGCGGACTCTG \\
\hline qNOS3-F & GATGCCGAAGCGAGTGAAG \\
\hline qNOS3-R & CACCAACACCAGCGTCTC \\
\hline qCAT1-F & TGAAGGCTCTCGTGGACAT \\
\hline qCAT1-R & GGACAGTATTTGGGTTGCTCATAA \\
\hline qCAT2-F & AGCCTGAGAGCAAGACCAA \\
\hline qCAT2-R & CGTAGCCGAAGTAGATGAAGAAG \\
\hline
\end{tabular}


Table 1. Cont.

\begin{tabular}{|c|c|}
\hline Primer Name & Primer Sequence $\left(5^{\prime} \text { to } 3^{\prime}\right)^{1}$ \\
\hline qIL-6-F & TTCAGTCCAGTCGCCTTCT \\
\hline qIL-6-R & TCACACATCTССТTТСТСАTTGC \\
\hline qGM-CSF-F & AGACTCGCCTGAACCTGTA \\
\hline qGM-CSF-R & TGCTGCTCATAGTGCTTGG \\
\hline qCCL-2-F & GTCACCTGCTGCTATACACTTAC \\
\hline qCCL-2-R & ATCACTGCTTCTTTAGGACACTTG \\
\hline cydA-F & AGGCTTAATGGCGTTCTTCTTAG \\
\hline cydA-R & GCATCCAACCGTTAGCAACTA \\
\hline cydB-F & CAATGTTGAACGCCGTGTAATG \\
\hline cydB-R & GGAAGAATAATGCCGCTAGAACT \\
\hline pflA-F & GCCACAACCGTGACACTT \\
\hline pflA-R & CGCCACCTGATGCTGTTAC \\
\hline pflB-F & GCGATTGCCTGCTGTGTAA \\
\hline pflB-R & GCCATTGATTGCGTATAGTAAGGT \\
\hline adhE-F & CAACAAGGCTGGCGAGTAAT \\
\hline adhE-R & GGCTGAGTTAGTCACATCAAGTT \\
\hline nrdD-F & CGGAGGTTCGGCATTACATC \\
\hline nrdD-R & TGGTCACAGGTGTTACATAAGGT \\
\hline nrdG-F & CTTGGAAGCGGTCAGATTCTC \\
\hline nrdG-R & AATAACAATTCAGGCAACCACTCT \\
\hline napA-F & CGCTTAACCTCGCCAATGT \\
\hline napA-R & TGATTGACCTGAAGTGAACATACC \\
\hline napD-F & GTGAAGCAAGCCTTAACTGAGT \\
\hline napD-R & CAGCGACACCACGATAACC \\
\hline nrfC-F & CTGTGTTGGTTGTGCTTATTGC \\
\hline $\operatorname{nrfC}-\mathrm{R}$ & CGAATGTTAGTGCTTTGGTTGGA \\
\hline nrfD-F & GGATTCAACCATTGCGATCTATCT \\
\hline nrfD-R & AGCGGTGACATTATTGCCATT \\
\hline $16 \mathrm{~S}$ rRNA-F & TGAAGTCGGAATCGCTAGTA \\
\hline 16S rRNA-R & CCTACGGTTACCTTGTTACG \\
\hline siIRF1-1-F & CCAACUUUCGCUGUGCCAUTT \\
\hline siIRF1-1-R & AUGGCACAGCGAAAGUUGGTT \\
\hline siIRF1-2-F & GGACAUUGAACAGGCCCUUTT \\
\hline siIRF1-2-R & AAGGGCCUGUUCAAUGUCCTT \\
\hline
\end{tabular}

${ }^{1}$ All restriction sites are indicated in Red.

\subsection{Western Blotting}

Cells were seeded in $60-\mathrm{mm}$ dishes at $2 \times 10^{6}$ cells/dish and grown until confluent. After specific treatment, cells were collected and lysed in $500 \mu \mathrm{L}$ of Western blot lysis buffer (Beyotime, Shanghai, China) supplemented with the proteinase inhibitor phenylmethylsulfonyl fluoride (Sigma-Aldrich). The protein concentration was determined by the bicinchoninic acid assay (BIOSHARP, Hefei, China), and equivalent amounts of protein were separated on sodium dodecyl sulfate polyacrylamide gel electrophoresis ( $5 \%-12 \%$ polyacrylamide) and then transferred to a polyyinylidene difluoride membrane. The membrane was blocked with $5 \%$ bovine serum albumin (BSA) in $0.1 \mathrm{M}$ Tris-buffer saline ( $\mathrm{pH} 7.5$ ) containing $0.05 \%$ Tween-20 (TBST) for at least $1 \mathrm{~h}$, and then probed overnight with appropriate primary antibodies against as follows: IкB- $\alpha, p-p 65, p 65$ or $\beta$-actin $(1: 2000$ in $5 \%$ BSA in TBST; Cell Signaling Technology, Danvers, MA, USA). They were then incubated with anti-mouse or anti-rabbit horseradish peroxidase-conjugated secondary antibodies for $2 \mathrm{~h}$ at $37^{\circ} \mathrm{C}$. Blots were finally visualized with ECL reagents (Bio-Rad, Hercules, CA, USA) via chemiluminescence. To compare reaction intensities, average band densities were determined using Quantity One software (Bio-Rad). 


\subsection{RNA Isolation and Real-Time PCR}

Total RNA from cells or bacteria was extracted using Trizol reagent (Invitrogen, Carlsbad, CA, USA) according to the manufacturer's guidelines. DNase I (New England Biolabs, Ipswich, MA, USA) was applied to remove residual genomic DNA for the following reverse transcription (RT) reactions (Takara Bio Inc., Shiga, Japan). mRNA transcription levels were determined using the Power SYBR Green PCR master mix (Applied Biosystems, Foster City, CA, USA) according to standard instructions. Primers used for RT-PCR and real-time PCR are listed in Table 1. GAPDH was used as the internal reference for 3D4/21 cells and the specific $16 \mathrm{~S}$ rRNA was used as the control for G. parasuis. The $2^{-\Delta \Delta C T}$ method was used to calculate relative gene expression.

\subsection{Statistical Analysis}

The significance of the differences between each group was analyzed by two-way analysis of variance (ANOVA) embedded in GraphPad Prism version 6.0 and Student's $t$-tests. The $p$-value $<0.05$ $\left(^{*}\right)$ was statistically significant, and both $p<0.01\left(^{* *}\right)$ and $p<0.001\left(^{* * *}\right)$ were considered extremely significant.

Author Contributions: Q.C. and X.W. conceived and designed the research. Q.C., H.W., W.W., Y.L. and Z.W. performed the experiments. Q.C., H.W. and X.W. analyzed the data. X.X., X.C. and H.C. contributed reagents/materials/analysis tools. Q.C. and X.W. drafted and revised the paper.

Funding: This work was supported by grants from the National Natural Science Foundation of China (31772736), the earmarked fund for China Agriculture Research System (CARS-35), the Outstanding youth project of Natural Science Foundation in Hubei Province (2018CFA070) and the Fundamental Research Funds for the Central Universities (Program No. 2662018PY032).

Acknowledgments: We thank Sarah Williams, PhD, from Liwen Bianji, Edanz Group China (www.liwenbianji.cn) for editing the English text of a draft of this manuscript.

Conflicts of Interest: The authors declare no conflict of interest.

Ethical Statement: The 3D4/21 cell line and HEK293T cell line were obtained from ATCC. The pGL3-luciferase and pRL-TK reporter plasmids were obtained from Promega (Beijing) Biotech Co., Ltd. The pcDNA3.1(+) vector was obtained from Thermo Fisher Scientific (China) Co., Ltd.

\section{References}

1. Costa-Hurtado, M.; Olvera, A.; Martinez-Moliner, V.; Galofre-Mila, N.; Martinez, P.; Dominguez, J.; Aragon, V. Changes in macrophage phenotype after infection of pigs with Haemophilus parasuis strains with different levels of virulence. Infect. Immun. 2013, 81, 2327-2333. [CrossRef]

2. Oliveira, S.; Pijoan, C. Haemophilus parasuis: New trends on diagnosis, epidemiology and control. Vet. Microbiol. 2004, 99, 1-12. [CrossRef]

3. Cai, X.; Chen, H.; Blackall, P.J.; Yin, Z.; Wang, L.; Liu, Z.; Jin, M. Serological characterization of Haemophilus parasuis isolates from China. Vet. Microbiol. 2005, 111, 231-236. [CrossRef]

4. Correa-Fiz, F.; Fraile, L.; Aragon, V. Piglet nasal microbiota at weaning may influence the development of Glasser's disease during the rearing period. BMC Genom. 2016, 17, 404. [CrossRef]

5. Costa-Hurtado, M.; Aragon, V. Advances in the quest for virulence factors of Haemophilus parasuis. Vet. J. 2013, 198, 571-576. [CrossRef]

6. Olvera, A.; Ballester, M.; Nofrarias, M.; Sibila, M.; Aragon, V. Differences in phagocytosis susceptibility in Haemophilus parasuis strains. Vet. Res. 2009, 40, 24. [CrossRef]

7. Crosara-Alberto, D.P.; Darini, A.L.; Inoue, R.Y.; Silva, J.S.; Ferreira, S.H.; Cunha, F.Q. Involvement of NO in the failure of neutrophil migration in sepsis induced by Staphylococcus aureus. Br. J. Pharmacol. 2002, 136, 645-658. [CrossRef] [PubMed]

8. Geissmann, F.; Gordon, S.; Hume, D.A.; Mowat, A.M.; Randolph, G.J. Unravelling mononuclear phagocyte heterogeneity. Nat. Rev. Immunol. 2010, 10, 453-460. [CrossRef] [PubMed]

9. Liu, C.; Wang, Y.; Zhang, H.; Cheng, S.; Charreyre, C.; Audonnet, J.C.; Chen, P.; He, Q. Porcine coronin $1 \mathrm{~A}$ contributes to nuclear factor-kappa B (NF-kappaB) inactivation during Haemophilus parasuis infection. PLOS ONE 2014, 9, e103904. 
10. Buzzo, C.L.; Campopiano, J.C.; Massis, L.M.; Lage, S.L.; Cassado, A.A.; Leme-Souza, R.; Cunha, L.D.; Russo, M.; Zamboni, D.S.; Amarante-Mendes, G.P.; et al. A novel pathway for inducible nitric-oxide synthase activation through inflammasomes. J. Biol. Chem. 2010, 285, 32087-32095. [CrossRef] [PubMed]

11. Newton, K.; Dixit, V.M. Signaling in innate immunity and inflammation. Cold Spring Harb. Perspect. Biol. 2012, 4, a006049. [CrossRef] [PubMed]

12. Bogdan, C. Nitric oxide and the immune response. Nat. Immunol. 2001, 2, 907-916. [CrossRef] [PubMed]

13. Green, S.J.; Mellouk, S.; Hoffman, S.L.; Meltzer, M.S.; Nacy, C.A. Cellular mechanisms of nonspecific immunity to intracellular infection: Cytokine-induced synthesis of toxic nitrogen oxides from L-arginine by macrophages and hepatocytes. Immunol. Lett. 1990, 25, 15-19. [CrossRef]

14. Rao, K.M. Molecular mechanisms regulating iNOS expression in various cell types. J. Toxicol. Environ. Health B Crit. Rev. 2000, 3, 27-58. [CrossRef] [PubMed]

15. Peunova, N.; Enikolopov, G. Nitric oxide triggers a switch to growth arrest during differentiation of neuronal cells. Nature 1995, 375, 68-73. [CrossRef] [PubMed]

16. Duran, W.N.; Breslin, J.W.; Sanchez, F.A. The NO cascade, eNOS location, and microvascular permeability. Cardiovasc. Res. 2010, 87, 254-261. [CrossRef]

17. MacMicking, J.; Xie, Q.W.; Nathan, C. Nitric oxide and macrophage function. Annu. Rev. Immunol. 1997, 15, 323-350. [CrossRef]

18. Li, H.; Poulos, T.L. Structure-function studies on nitric oxide synthases. J. Inorg. Biochem. 2005, 99, $293-305$. [CrossRef]

19. Nathan, C. Nitric oxide as a secretory product of mammalian cells. FASEB J. 1992, 6, 3051-3064. [CrossRef]

20. Hung, C.Y.; Castro-Lopez, N.; Cole, G.T. Card9- and MyD88-Mediated Gamma Interferon and Nitric Oxide Production Is Essential for Resistance to Subcutaneous Coccidioides posadasii Infection. Infect. Immun. 2016, 84, 1166-1175. [CrossRef]

21. Bogdan, C.; Rollinghoff, M.; Diefenbach, A. Reactive oxygen and reactive nitrogen intermediates in innate and specific immunity. Curr. Opin. Immunol. 2000, 12, 64-76. [CrossRef]

22. Fang, F.C. Antimicrobial reactive oxygen and nitrogen species: Concepts and controversies. Nat. Rev. Microbiol. 2004, 2, 820-832. [CrossRef] [PubMed]

23. Jones-Carson, J.; Laughlin, J.; Hamad, M.A.; Stewart, A.L.; Voskuil, M.I.; Vazquez-Torres, A. Inactivation of [Fe-S] metalloproteins mediates nitric oxide-dependent killing of Burkholderia mallei. PLoS ONE 2008, 3, e1976. [CrossRef] [PubMed]

24. Richardson, A.R.; Payne, E.C.; Younger, N.; Karlinsey, J.E.; Thomas, V.C.; Becker, L.A.; Navarre, W.W.; Castor, M.E.; Libby, S.J.; Fang, F.C. Multiple targets of nitric oxide in the tricarboxylic acid cycle of Salmonella enterica serovar typhimurium. Cell Host Microbe 2011, 10, 33-43. [CrossRef]

25. Allan, R.N.; Morgan, S.; Brito-Mutunayagam, S.; Skipp, P.; Feelisch, M.; Hayes, S.M.; Hellier, W.; Clarke, S.C.; Stoodley, P.; Burgess, A. Low Concentrations of Nitric Oxide Modulate Streptococcus pneumoniae Biofilm Metabolism and Antibiotic Tolerance. Antimicrob. Agents Chemother. 2016, 60, 2456-2466. [CrossRef]

26. Langrehr, J.M.; Hoffman, R.A.; Billiar, T.R.; Lee, K.K.; Schraut, W.H.; Simmons, R.L. Nitric oxide synthesis in the in vivo allograft response: A possible regulatory mechanism. Surgery 1991, 110, 335-342.

27. Annane, D.; Sanquer, S.; Sebille, V.; Faye, A.; Djuranovic, D.; Raphael, J.C.; Gajdos, P.; Bellissant, E. Compartmentalised inducible nitric-oxide synthase activity in septic shock. Lancet 2000, 355, 1143-1148. [CrossRef]

28. Brown, G.C.; Neher, J.J. Inflammatory neurodegeneration and mechanisms of microglial killing of neurons. Mol. Neurobiol. 2010, 41, 242-247. [CrossRef]

29. Rasheed, Z.; Al-Shobaili, H.A.; Rasheed, N.; Mahmood, A.; Khan, M.I. MicroRNA-26a-5p regulates the expression of inducible nitric oxide synthase via activation of NF-kappaB pathway in human osteoarthritis chondrocytes. Arch. Biochem. Biophys. 2016, 594, 61-67. [CrossRef]

30. Jimenez Mdel, P.; Walls, L.; Fierer, J. High levels of interleukin-10 impair resistance to pulmonary coccidioidomycosis in mice in part through control of nitric oxide synthase 2 expression. Infect. Immun. 2006, 74, 3387-3395. [CrossRef]

31. Moreira, A.P.; Dias-Melicio, L.A.; Peracoli, M.T.; Calvi, S.A.; Victoriano de Campos Soares, A.M. Killing of Paracoccidioides brasiliensis yeast cells by IFN-gamma and TNF-alpha activated murine peritoneal macrophages: Evidence of $\mathrm{H}(2) \mathrm{O}$ (2) and NO effector mechanisms. Mycopathologia 2008, 166, 17-23. [CrossRef] [PubMed] 
32. von Bargen, K.; Wohlmann, J.; Taylor, G.A.; Utermohlen, O.; Haas, A. Nitric oxide-mediated intracellular growth restriction of pathogenic Rhodococcus equi can be prevented by iron. Infect. Immun. 2011, 79, $2098-2111$. [CrossRef] [PubMed]

33. van Sorge, N.M.; Beasley, F.C.; Gusarov, I.; Gonzalez, D.J.; von Kockritz-Blickwede, M.; Anik, S.; Borkowski, A.W.; Dorrestein, P.C.; Nudler, E.; Nizet, V. Methicillin-resistant Staphylococcus aureus bacterial nitric-oxide synthase affects antibiotic sensitivity and skin abscess development. J. Biol. Chem. 2013, 288, 6417-6426. [CrossRef] [PubMed]

34. Gusarov, I.; Nudler, E. NO-mediated cytoprotection: Instant adaptation to oxidative stress in bacteria. Proc. Natl. Acad. Sci. USA 2005, 102, 13855-13860. [CrossRef] [PubMed]

35. Shatalin, K.; Gusarov, I.; Avetissova, E.; Shatalina, Y.; McQuade, L.E.; Lippard, S.J.; Nudler, E. Bacillus anthracis-derived nitric oxide is essential for pathogen virulence and survival in macrophages. Proc. Natl. Acad. Sci. USA 2008, 105, 1009-1013. [CrossRef] [PubMed]

36. Kers, J.A.; Wach, M.J.; Krasnoff, S.B.; Widom, J.; Cameron, K.D.; Bukhalid, R.A.; Gibson, D.M.; Crane, B.R.; Loria, R. Nitration of a peptide phytotoxin by bacterial nitric oxide synthase. Nature 2004, 429, 79-82. [CrossRef] [PubMed]

37. Xu, Z.; Yue, M.; Zhou, R.; Jin, Q.; Fan, Y.; Bei, W.; Chen, H. Genomic characterization of Haemophilus parasuis SH0165, a highly virulent strain of serovar 5 prevalent in China. PLoS ONE 2011, 6, e19631. [CrossRef]

38. Nicholson, B.; Manner, C.K.; Kleeman, J.; MacLeod, C.L. Sustained nitric oxide production in macrophages requires the arginine transporter CAT2. J. Biol. Chem. 2001, 276, 15881-15885. [CrossRef]

39. Chen, M.; Bao, W.; Aizman, R.; Huang, P.; Aspevall, O.; Gustafsson, L.E.; Ceccatelli, S.; Celsi, G. Activation of extracellular signal-regulated kinase mediates apoptosis induced by uropathogenic Escherichia coli toxins via nitric oxide synthase: Protective role of heme oxygenase-1. J. Infect. Dis. 2004, 190, 127-135. [CrossRef]

40. Nakatsubo, N.; Kojima, H.; Kikuchi, K.; Nagoshi, H.; Hirata, Y.; Maeda, D.; Imai, Y.; Irimura, T.; Nagano, T. Direct evidence of nitric oxide production from bovine aortic endothelial cells using new fluorescence indicators: Diaminofluoresceins. FEBS Lett. 1998, 427, 263-266. [CrossRef]

41. Kinkel, T.L.; Roux, C.M.; Dunman, P.M.; Fang, F.C. The Staphylococcus aureus SrrAB two-component system promotes resistance to nitrosative stress and hypoxia. MBio 2013, 4, e00696-13. [CrossRef] [PubMed]

42. Chen, Y.; Jin, H.; Chen, P.; Li, Z.; Meng, X.; Liu, M.; Li, S.; Shi, D.; Xiao, Y.; Wang, X. Haemophilus parasuis infection activates the NF-kappaB pathway in PK-15 cells through IkappaB degradation. Vet. Microbiol. 2012, 160, 259-263. [CrossRef] [PubMed]

43. Upreti, M.; Kumar, S.; Rath, P.C. Replacement of 198MQMDII203 of mouse IRF-1 by 197IPVEVV202 of human IRF-1 abrogates induction of IFN-beta, iNOS, and COX-2 gene expression by IRF-1. BioChem. Biophys. Res. Commun. 2004, 314, 737-744. [CrossRef] [PubMed]

44. Wink, D.A.; Hines, H.B.; Cheng, R.Y.; Switzer, C.H.; Flores-Santana, W.; Vitek, M.P.; Ridnour, L.A.; Colton, C.A. Nitric oxide and redox mechanisms in the immune response. J. Leukoc. Biol. 2011, 89, 873-891. [CrossRef]

45. Chan, J.; Tanaka, K.; Carroll, D.; Flynn, J.; Bloom, B.R. Effects of nitric oxide synthase inhibitors on murine infection with Mycobacterium Tuberculosis. Infect. Immun. 1995, 63, 736-740.

46. Cho, W.S.; Chae, C. Expression of nitric oxide synthase 2 and cyclooxygenase-2 in swine experimentally infected with Actinobacillus pleuropneumoniae. Vet. Pathol. 2004, 41, 666-672. [CrossRef]

47. Rocco, N.M.; Carmen, J.C.; Klein, B.S. Blastomyces dermatitidis yeast cells inhibit nitric oxide production by alveolar macrophage inducible nitric oxide synthase. Infect. Immun. 2011, 79, 2385-2395. [CrossRef]

48. Pampusch, M.S.; Bennaars, A.M.; Harsch, S.; Murtaugh, M.P. Inducible nitric oxide synthase expression in porcine immune cells. Vet. Immunol. Immunopathol. 1998, 61, 279-289. [CrossRef]

49. Sekine, N.; Fukumoto, S.; Ishikawa, T.; Okazaki, T.; Fujita, T. GH inhibits interferon-gamma-induced signal transducer and activator of transcription-1 activation and expression of the inducible isoform of nitric oxide synthase in INS-1 cells. Endocrinology 2001, 142, 3909-3916. [CrossRef]

50. Gao, J.; Morrison, D.C.; Parmely, T.J.; Russell, S.W.; Murphy, W.J. An interferon-gamma-activated site (GAS) is necessary for full expression of the mouse iNOS gene in response to interferon-gamma and lipopolysaccharide. J. Biol. Chem. 1997, 272, 1226-1230. [CrossRef]

51. Xiong, H.; Zhu, C.; Li, H.; Chen, F.; Mayer, L.; Ozato, K.; Unkeless, J.C.; Plevy, S.E. Complex formation of the interferon (IFN) consensus sequence-binding protein with IRF-1 is essential for murine macrophage IFN-gamma-induced iNOS gene expression. J. Biol. Chem. 2003, 278, 2271-2277. [CrossRef] [PubMed] 
52. Burke, S.J.; Updegraff, B.L.; Bellich, R.M.; Goff, M.R.; Lu, D.; Minkin, S.C.; Karlstad, M.D.; Collier, J.J. Regulation of iNOS gene transcription by IL-1beta and IFN-gamma requires a coactivator exchange mechanism. Mol. Endocrinol. 2013, 27, 1724-1742. [CrossRef] [PubMed]

53. Jung, J.Y.; Madan-Lala, R.; Georgieva, M.; Rengarajan, J.; Sohaskey, C.D.; Bange, F.C.; Robinson, C.M. The intracellular environment of human macrophages that produce nitric oxide promotes growth of mycobacteria. Infect. Immun. 2013, 81, 3198-3209. [CrossRef] [PubMed]

54. Heinecke, J.L.; Ridnour, L.A.; Cheng, R.Y.; Switzer, C.H.; Lizardo, M.M.; Khanna, C.; Glynn, S.A.; Hussain, S.P.; Young, H.A.; Ambs, S.; et al. Tumor microenvironment-based feed-forward regulation of NOS2 in breast cancer progression. Proc. Natl. Acad. Sci. USA 2014, 111, 6323-6328. [CrossRef]

55. Vareille, M.; de Sablet, T.; Hindre, T.; Martin, C.; Gobert, A.P. Nitric oxide inhibits Shiga-toxin synthesis by enterohemorrhagic Escherichia coli. Proc. Natl. Acad. Sci. USA 2007, 104, 10199-10204. [CrossRef]

56. Branchu, P.; Matrat, S.; Vareille, M.; Garrivier, A.; Durand, A.; Crepin, S.; Harel, J.; Jubelin, G.; Gobert, A.P. NsrR, GadE, and GadX interplay in repressing expression of the Escherichia coli O157, H7 LEE pathogenicity island in response to nitric oxide. PLoS Pathog. 2014, 10, e1003874. [CrossRef]

57. Urbano, R.; Karlinsey, J.E.; Libby, S.J.; Doulias, P.T.; Ischiropoulos, H.; Warheit-Niemi, H.I.; Liggitt, D.H.; Horswill, A.R.; Fang, F.C. Host Nitric Oxide Disrupts Microbial Cell-to-Cell Communication to Inhibit Staphylococcal Virulence. Cell Host Microbe 2018, 23, 594-606. [CrossRef]

58. Nittler, M.P.; Hocking-Murray, D.; Foo, C.K.; Sil, A. Identification of Histoplasma capsulatum transcripts induced in response to reactive nitrogen species. Mol. Biol. Cell 2005, 16, 4792-4813. [CrossRef]

59. Bang, I.S.; Liu, L.; Vazquez-Torres, A.; Crouch, M.L.; Stamler, J.S.; Fang, F.C. Maintenance of nitric oxide and redox homeostasis by the salmonella flavohemoglobin hmp. J. Biol. Chem. 2006, 281, 28039-28047. [CrossRef]

60. Huang, J.; Wang, X.; Cao, Q.; Feng, F.; Xu, X.; Cai, X. ClpP participates in stress tolerance and negatively regulates biofilm formation in Haemophilus parasuis. Vet. Microbiol. 2016, 182, 141-149. [CrossRef]

(C) 2019 by the authors. Licensee MDPI, Basel, Switzerland. This article is an open access article distributed under the terms and conditions of the Creative Commons Attribution (CC BY) license (http://creativecommons.org/licenses/by/4.0/). 